\section{W.V. Slack}

Division of Clinical Computing, Departments of Medicine and Psychiatry,

Harvard Medical School and Beth Israel Center for Clinical Computing, Deaconess Medical Center and Boston, MA, USA

\section{Review Paper}

\section{Patient-Computer Dialogue: A Review ${ }^{1,2}$}

\begin{abstract}
Since the first study of communication between patient and computer was performed at the University of Wisconsin in 1965, programs for patient-computer dialogue have been developed, implemented, and studied in numerous settings in the United States and abroad, and the results have been encouraging. This review presents a brief history of patient-computer dialogue together with suggested guidelines for programs in the future.
\end{abstract}

Keywords: cybermedicine, patient-computer dialogue, computers, interviews, medical history taking, user-computer interface, self-care, patient power, patient satisfaction.

\section{Introduction}

Dialogue between doctor and patient is the mainstay of clinical medicine. During the interpersonal encounter, the doctor tries to establish rapport, develop bonds of mutual respect and trust, collect information relevant to a patient's medical problems and general health, and communicate information for the patient's immediate and long-range use. In turn, the patient can explain his or her wishes to the doctor, and the two can work together to develop an approach to treatment consistent with both the patient's wishes and the dictates of medical science [1]. Even in the best of circumstances, however, practicing physicians are faced with serious problems when it comes to dialogue with their patients. Clinical interviewing requires a large amount of time, and inadequate histories and insufficient counseling often result from limitations in time beyond the physician's control. Furthermore, recording the medical history in longhand is a laborious process, and the record is frequently incomplete and illegible - characteristics that hamper the retrieval of information and, hence, the use of the record in patient care and research [2]. Dictation and transcription, which overcome some of these problems for the physician, introduce a third party and a potential source of error.

Since the Second World War, advances in medical care have outstripped our ability to apply them, and pressures on health care systems worldwide have escalated. Doctors are pressured on the one hand by increasingly empowered patients, who understandably want and expect more personal attention, and on the other hand by parsimonious bureaucrats, who schedule more patients in shorter intervals. There is a pressing need, therefore, to seek new ways to enhance medical communication and thereby supplement the interpersonal relation- ship between doctor and patient. The idea is not to replace the doctor; the idea is to fill a void.

Since early times, growth in population has been accompanied by innovation in communication - inventions that enhance the exchange of information between more and more people, but that do so at the expense of direct interpersonal conversation [3]. Each invention has been subject to early criticism both by the well-meaning humanist, who objects to anything seen as having a depersonalizing influence, and by the well-meaning traditionalist, who opposes innovation on principle. Novelty is unsettling. It is hard to assess the potential of a new idea. This is true in virtually all walks of life - the arts, the sciences, the marketplace, and the professions. As Machiavelli observed, "The innovator makes en-

\section{Early Technology}

\footnotetext{
Supported in part by research funds from the Center for Clinical Computing

2 Portions of this manuscript were adapted from Cybermedicine: How Computing Empowers Doctors and Patients for Better Health Care (San Trancisco: Jossey-Bass, 1997), with the permission of the publisher.
} 
emies of all those who prospered under the old order" [4]. It is likely that when the ingenious Summerian who invented writing first carved those cuneiform symbols in stone along the Tigris River some six thousand years ago, a skeptic standing nearby predicted with concerned countenance that people would soon stop talking to each other. Those who read the $R e$ public in school will remember that Plato was very much opposed to theater as it was performed in ancient Greece. For him the portrayal of fictional characters was an ignoble pursuit that exposed audiences to the risk of corruption.

When Johannes Gutenberg invented the printing press in the mid-fifteenth century, he used his invention to publish the first printed version of the Christian Bible. His machine, controversial at the time of its inception, would, of course, have an enormous influence on secular communication, although the medical profession would be slow to adopt the printed word as a means of communication with patients. Patients were to be kept in the dark, knowing only what their doctors wanted them to know. (When the doctor handed the patient a prescription it was written in Latin to prevent communication.) But in 1946 came a turning point in medical publications for the public. Pocket Books published Baby and Child Care, by Benjamin Spock [5]. Criticized at first by the American Medical Association (AMA) for pandering to the public, Spock's book so obviously filled a niche that it could not be stifled. It told how to care for a sick baby when the doctor was not readily available; it advised parents about caring for their baby at home and about when to call a doctor. Spock legitimized the medical book for the American public, and publications on selfcare are now published in abundance, many with the blessing of the AMA. The old adage, "The person who treats himself has a fool for a doctor," is being replaced by titles such as How to Be Your Own Doctor.

By the 1960 s, patients and physicians were using self-administered paper questionnaires with considerable success. For example, the Cornell Medical Index [6,7] and the "multiphasic" questionnaire of the Permanente Medical Group [8] provided standardized, consistent, and inexpensive methods for taking medical histories. And many good self-administered medical questionnaires are used throughout the world today. Although paper questionnaires are helpful in collecting information, they cannot be tailored to the particular needs of the individual because they permit no interaction. They provide no mechanism either to clarify a question or to qualify an answer, so that a patient may misunderstand a question and therefore give an erroneous answer. Patients may inadvertently skip questions or lose one or more pages of a paper questionnaire. Furthermore, filling out questionnaires can be drudgery for many people.

\section{Enter the Computer}

The digital computer, and more recently the personal computer, is the newestmedium of communication. And again, the initial reaction was unfavorable. "I think there is a world market for maybe five computers," Thomas Watson, chairman of IBM, is purported to have said in 1943.

The essence of the computer, in contrast to the printed document, is its ability to interact, to converse with its user one on one. With this capability in mind, my colleagues and I at the University of Wisconsin had the hypothesis that we could program a computer to interact directly with a patient, to explore medical problems in detail and to do so in a personalized, courteous, and considerate manner. The idea of a patient "talking" to a computer was hotly debated at its inception in the 1960 s and is still controversial in many quarters. On the other hand, there were theoretical reasons for pursuing this idea. Could the computer actually model the physician as an interviewer? And there were practical reasons as well. We hoped that the interactive, computer-based interview would help doctors care for their patients and that using the computer would be of interest, perhaps even enjoyable, for patients themselves. Furthermore, in the back of my mind was the idea that the computer might actually help patients to help themselves with their medical problems [9-11].

We used the LINC (laboratory instrument computer) [12] for our first interview, a medical history of allergies [2]. Questions and comments were presented to the patient on the LINC's cathode-ray screen, and the patient responded by pressing keys on the keyboard. This was a branching program, with presentations by the computer contingent on the patient's responses. At the conclusion of the interview, the computer generated a summary for the patient and his or her physician, printed in a legible but otherwise traditional format. In a formal study, we found that patients communicated more relevant medical information to the computer than they had to their doctors. At the end of the interview, the computer asked each patient what he or she had thought of the experience. As we had hoped, almost all the patients found their interaction with the computer both interesting and enjoyable.

Encouraged by our early results, we pressed on with further studies of patient-computer dialogue, in our laboratories at the University of Wisconsin and, more recently, at Beth Israel Deaconess Medical Center in Boston. Our programs dealt with a wide variety of medical and psychological problems and were well received by pa- 
tients and physicians alike [13-24]. In the meantime, others began to work in the field; studies at the Mayo Clinic $[25,26]$, the Marshfield Clinic [27], the Massachusetts General Hospital [28], the University of Utah [29], Duke University [30], and other medical centers in the United States and abroad [31-51] yielded encouraging results. And research with patient-computer dialogue continues to this day [52-60].

In our experience, and the experience of most others who have studied dialogue between patient and computer, concern about the computer as adepersonalizing influence in dialogue withpatients has been unfounded. Most patients who have used our programs have found their experience to be pleasant, interesting, and informative $[2,24,61]$. Other investigators have found the same positive reaction $[25,40,42,43,47]$. On the other hand, when we have asked patients to compare the computer with doctors in their experience, the responses tend to be mixed. Sometimes people have responded "yes" to preferring the computer and "yes" to preferring the doctor, apparently not wanting to hurt anyone's feelings and nicely demonstrating that human beings are not always Aristotelian in their logic.

Growing interest in computer-based interviewing led to efforts to develop programming languages that would facilitate conversation between person and machine [62-64]. Among these, Converse, which was designed in our laboratory, provides a means to construct, edit, test, and operate computer-based interviews in English, French, Spanish, and Portuguese, and to generate printed summaries in English [65]. With this program, the course of the interview can be determined by multiple contingencies, and the wording presented on the screen can be modified in response to information obtained from the patient. Converse, which can be used to teach, to test, to counsel, and to query, remains in rou- tine use at Beth Israel Deaconess and Brigham and Women's hospitals as well as in places of export [3].

\section{The Computer as a Patient's Assistant}

The next step in our studies was to use Converse to develop programs that would help patients help themselves as well as their physicians - to explore the idea that an interactive computer could model the clinician and provide direct consultation to patients regarding the management of common, important medical problems [3]. Coupled with this work was my conviction that patients should be offered the opportunity to make their own medical decisions, particularly when value judgments are involved $[66,67]$. For starters, we developed a dietarycounseling program that asks about general dietary behavior, elicits details of food intake on an average day, and helps the patient plan a 1200 to 1700 calorie weight-reducing diet. Computer-generated printed summaries include estimates of the caloric content of food portions and details of the proposed diet. Volunteers reacted favorably to the program and gained valuable insight into their eating behavior from the computer sessions $[68,69]$.

We also developed a program for women with urinary tract infections. The program takes a history of the present illness, performs a review of systems, provides instruction for the collection of a clean voided urine specimen, interprets laboratory data, decides whether a patient needs referral to a physician, tests the reliability of the patient's responses by reasking selected questions, addresses the patient's uncertainties, explains the diagnostic and therapeutic options, offers opportunities to review information, incorporates the patient's decisions into therapeutic choices, writes a prescription for antimicrobial therapy, writes a progress note for the chart, schedules a follow-up visit, writes a summary (with reminders) for the patient, conducts a follow-up interview, and guides the progress of therapy. In a preliminary clinical trial, the program performed to the satisfaction of the patients and researchers $[3,70]$. Upon leaving the session, patients spoke approvingly of their time with the computer: "No doctor has ever been as thorough with me as your machine" and "I hope you will have similar programs for other medical problems" were among the comments. And the majority of patients liked being able to make their own decisions about treatment. I am convinced that clinically informed patients are more likely to comply with their own decisions than with decisions dictated to them [67].

Urinary tract infection is a medical problem traditionally in the therapeutic province of the physician. Sulfa, the treatment of choice in most instances, requires a physician's prescription. In our studies, all the computer-generated prescriptions were signed by one of the participating doctors. We hope this will be but a temporary expedient, however, necessary only to conform with current regulations. I can think of no good reason why patients with uncomplicated urinary tract infection cannot prescribe for themselves, at least with the help of the computer. And the results of our research corroborate this judgment. If problems such as urinary tract infection can be managed in the home instead of the clinic, the cost savings will be substantial, and the quality of care can be at least as good, if not better than in the traditional clinical setting [3].

More recently, we developed a computer-administered health screening and counseling interview for hospital employees and staff clinicians [71]. The interview is part of the integrated Center for Clinical Computing (CCC) clinical information system used throughout Beth Israel Deaconess 
Medical Center, and is available on any of six thousand terminals $[72,73]$. Conducted in private and with protection of confidentiality, the interview seeks information on medical problems and patterns of living for which behavioral change is considered desirable, and offers advice and suggestions on matters of health and illness. During the past nine years, over 32 hundred employees have completed the interviews, and most have found the experience worthwhile and pleasant. Furthermore, approximately half of those who have taken the interview responded "yes" to the question "Did you sometimes want to tell the computer more than it asked?"

Others have also been working in the field. Interactive programs for patients with a variety of medical problems, such as venereal disease, diseases of the prostate gland, AIDS, breast cancer, and hypertension have been studied with encouraging results [74-80].

\section{Nonverbal Information}

Early computer-based interviews were insensitive to nonverbal information, such as posture, facial expression, and body movement, which the physician uses to assess the patient's emotional status and reliability as a respondent. It is difficult, however, to monitor and study the nonverbal behavior of a patient in a traditional medical interview. Furthermore, nonverbal cues that emanate from the interviewer can in turn introduce bias. As a result, little is known about the actual helpfulness of nonverbal information in the clinical process. The computer, on the other hand, has a unique advantage in the study of some types of nonverbal information. Accordingly, we developed a program that monitors a patient's heart rate and response latency during a computer interview and branches to different questions and comments con- tingent on this nonverbal information as well as the keyboard responses [81]. Research with this programpaved the way for subsequent studies of nonverbal information as part of the interviewing process, with findings such as a positive correlation between age and response latency in computer interviews $[82,83]$.

\section{The Computer in Psychotherapy}

Back in the 1960 s, Joseph Weizenbaum, Kenneth Colby, Michael McGuire, and their colleagues $[84,85]$ wrote several computer programs (Weizenbaum's was called Eliza after Shaw's heroine in Pygmalion) that took messages typed by the user, rephrased them with words of similar meaning, and responded in a manner suggestive of the nondirective psychotherapy first proposed by Carl Rogers [86].

Since then, a number of good programs have been developed and studied, and a wide variety of theoretical approaches have been employed. John Greist and his colleagues at the University of Wisconsin employed cognitive behavioral therapy in their program [87]. First elucidated by Aaron Beck and his coworkers, cognitive therapy consists of a didactic component, in which the therapist explains the approach to be taken (for example, in the treatment of depression); a cognitive component, in which the therapist elicits the patient's thoughts at the moment and helps the patient analyze the underlying maladaptive assumptions contributing to the depression; and a behavioral component, in which the therapist helps the patient plan thoughts and activities to supplant the depression [88]. Written in Converse, the Wisconsin program emulates the cognitive therapist. In a comparative study, the computer performed as well as the human therapist in reducing scores on tests of depression [87].
Computer-based cognitive behavioral therapy has also been used, with some reported success, for patients with early Alzheimer's disease and speech difficulties $[89,90]$.

In the early 1970s, my brother, Charles, and I began to study patientcomputer dialogue as an approach to psychotherapy. We reasoned that text on a computer screen could be a good stimulus for talk and that keyboard responses could be used to select text that would encourage talk about subjects of relevance to the person. Accordingly, we developed a computer program capable of controlling a tape recorder (and sensing when someone was talking into it) in conjunction with conducting a medical interview. With this program, people could be encouraged to talk aloud about theiremotional problems, and recorded messages could be left for the doctor at the patient's discretion. The computer, though noncomprehending as a listener, was informed as an interviewer. It could use information from keyboard responses to a psychiatric history to promote conversation appropriate to the individual patient.

We had three hypotheses: that the presence of a therapist is not essential in talking therapy, because patients will talk aloud alone about matters of psychological importance; that speaking out, as opposed to thinking quietly, is important to the effectiveness of psychotherapy; and that the doctorpatientrelationship, although often beneficial, can sometimes inhibit frank disclosure. In the latter case, soliloquy could actually be more effective than dialogue with a therapist.

Results of an early study were encouraging: analysis of the patient's spoken words, and the subjective reaction of the participants, suggested that the program had therapeutic value $[91,92]$. Furthermore, there was good reliability in the responses to questions presented by both a doctor and the computer [92]. More recently, we ex- 
tended the study of computer-assisted soliloquy to the treatment of anxiety [93]. In a controlled study, we found that talking aloud to the computer was more effective at lowering state anxiety scores [94] and heart rate [81] than thinkingquietly.

\section{Abreaction with the Computer}

Among proponents of traditional psychotherapy, it is widely held that topics of major psychological importance are, at least sometimes, the most unpleasant and hence the most difficult to discuss. It is also believed that reluctance to discuss such difficult topics must be removed if therapy is to be effective. This tenet is held whether the reluctance is interpreted as resistance to abreaction (bringing emotionally laden topics from the unconscious toconsciousness and open discussion), in accordance with the psychoanalytic concepts of Freud [95], or as resistance to extinction (the weakening of a conditioned response in the absence of reinforcing stimuli), in accordance with the behavioristic concepts of John Watson [96] and B.F. Skinner [97]. Furthermore, it is generally assumed that this resistance must be removed by means of the relationship established between patient and therapist.

Early on, however, I noticed that under some circumstances there is less resistance to such communication when it occurs in the absence of the human clinician [61]. Some patients have said that even when they were eager for their doctor to be informed, direct communication could be difficult, and indirect communication by means of the com/uter was easier for them [24]. This has been true as well with some of the volunteers in our studies of soliloquy [91,93].

This phenomenon, which might be called abreaction with the computer, has been corroborated by others, with some exceptions $[44,45]$. In one study, patients undergoing treatment for alcoholism found it easier to report high levels of alcohol consumption to the computer than to a psychiatrist [39]; and in other studies, patients were more likely to communicate to the computer about problems such as impotence, being fired from a job, and attempted suicide [41,57]. In addition, we have demonstrated that a computer-based screening interview could elicit more HIV-related factors in the health histories of potential blood donors than the standard questionnaire and interviewing methods currently in use at the Red Cross [54].

\section{The Patient Online}

Until 1980, patients had little direct access to computing. Patient-computer dialogue was for the most part limited to research projects in academic institutions that could afford computing facilities. Computing that extended outside of medical centers was anticipated but not present. As for computing in the home, this was but a dream for some and a pipe dream for others. There was, of course, the original handheld calculator, the Pocketronic, which was available in 1970 for $\$ 400$, but this was not considered a real computer [98]. As recently as the late 1970 s, it was common wisdom that computers would be impractical as domestic machines.

What most of us did not foresee was the personal computer, which would change our way of thinking forever. The first major breakthrough in personal computing software was the word processor, which replaced the typewriter almost as quickly as the calculator replaced the slide rule [98]. With rapid advances in technology and disk storage, the PC has carried us into a vast new electronic era. More and more PCs are available to more and more people from all walks of life.
Most middle-income families can afford a PC with modem, and world wide communication is now possible over the Internet. Numerous Web sites on the Internet offer a broad array of health related information. In 1998, over 70 million people turned to the Internet at least once [99]; 60 million of these were in search of medical information, and there is general agreement that the numbers are increasing exponentially.

For the most part, medical information on the Internet is presented in a didactic, noninteractive manner, but I am confident that the first decade of this millennium will be accompanied by interactive programs that address the individual needs of the people whoturn to them [100]. As with all medical literature directed to the patient, readers must be wary of information on the Internet and seek second and third opinions. There is misinformation on the Internet (as there is in printed material) as well as the useful and well founded. But if the user is careful to check the sources, helpful information can be retrieved on a wide variety of medical topics. Three of the United States government's sites / the National Library of Medicine (www.nlm.nih.gov), the Department of Health and Human Services (www.healthfinder.gov), and the Centers for Disease Control and Prevention (www.cdc.gov) / are examples, as are Howard Bleich's pioneering program, PaperChase, the first of its kind to offer user-friendly access to the Medline data base (www.Paper Chase.com) [101] and Samantha Scolamiero's pioneering mailing list [102].

\section{Guidelines for a Patient's Program}

My ideal interactive program for patients, whether it is on the Internet, a compact disk, or some other com- 
puter-based medium, would have the following characteristics, which we have tried to keep in mind as we have developed and studied the programs in our laboratories [3]:

The program should be medically sound. The authors' credentials and relevant experience should be readily available for scrutiny.

The program should be easy to use. It should be designed by people who understand the psychology of conversation with a computer, the human factors as well as the medical content. A few keystrokes or clicks of the mouse should be sufficient to gain access to the program, and moving from the opening words of welcome to the various options within the program should be a straightforward process. Ideally, the program should be addressed to the literacy level of the user, and written in the user's native language.

The program should be truly interactive. It should be easier for a person to obtain information from the computer than from a book. The program should be more than a page turner; the opposable thumb and forefinger are quite sufficient for this on their own, without the benefit of electronics. The program should be capable of responding quickly to the wishes and needs of the individual user. It should also proffer appropriate and potentially useful alternatives that the person has not yet thought of. It should be able to ask questions with respect and thoughtfulness, and answer questions in the same manner. When called upon to do so, the program should offer explanations, instructions, and suggestions.

The patient should be in charge. Provision should be made to respect the patient's right to decide as well as not to decide, and to respect the patient's reluctance to respond. Provision should be made to help the patient with uncertainty, when, for example, the patient doesn't know an answer or doesn't understand a question or comment. And provision should be made to respect the patient's priorities by requesting permission to proceed and offering alternatives from which the patient can choose during the course of the interview.

Confidentiality should be protected. Only the individual user or persons whom the user has authorized should have access to the information obtained during the dialogue $[103,104]$. The capability should exist, however, for pooling data from consenting users, who would remain anonymous, for use both in improving the program and in clinical research.

The computer should be fast and reliable. In the event of problems, help should be on hand.

The program should be subjected to formal study with volunteers in an experimental setting, before being offered to the public. Results of the study, including helpfulness and validity of the program, reliability of the items, and satisfaction of the volunteers, should be available to all who might subsequently want to use the program.

To my knowledge, no program yet exists that achieves this ideal. Certainly none of ours do. On the other hand, a number of people in the field are making progress, and I am optimistic.

\section{Acknowledgment}

I am indebted to Emily Boro, Hollis Kowaloff, and my other colleagues at theCenterforClinical Computing(Boston) and the University of Wisconsin for their many contributions to the work described in this article.

\section{References}

1. Slack WV. The computer and the doctorpatient relationship. MD Comput 1989;274:320-1.

2. Slack WV, Hicks GP, Reed CE, Van Cura LJ. A computer-based medical-history system. N Engl J Med 1966;274:194-8.

3. Slack WV. Cybermedicine:How Computing Empowers Doctors and Patients for Better Health Care. San Francisco: JosseyBass, 1997.

4. MachiavelliN.The Prince. (G. Bull, trans.) Harmondsworth, England: Penguin Books, 1981.

5. Spock B. Dr. Spock's Baby and Child Care: Sixth edition fully revised and updated for the 1990s. New York: NAL Dutton, 1992.

6. Brodman $\mathrm{K}$, Erdmann AJ Jr, Lorge I WolffHG. Cornell Medical Index:adjunct to medical interview, JAMA 1949;140:530-4.

7. Brodman $K$, Van Woerkom AJ, Erdmann AJ Jr, Goldstein LS. Interpretation of symptoms with data-processing machine. Arch Intern Med 1959;103:776-82.

8. Collen MF, Rubin L, Neyman J, Dantzig GB, Baer RM, Siegelaub AB. Automated multiphasic screening and diagnosis. Am J Public Health 1964;54:741-50.

9. SlackWV.Bravenewinterviewer. Harvard Med Alumni Bull 1966;69:44-9.

10. Slack WV.Patient-computer dialogue and the patient's right to decide. In: Bremnan PF, Schneider SJ. Tornquist E, eds. Information Networks for Community Health. New York: Springer-Verlag, 1997:55-69.

11. Slack WV. Cybermedicine:how computing empowers patients for better health care. In: Cesnik B, McCray AT, Scherrer $\mathrm{J}-\mathrm{R}$, eds. Proceedings Medinfo 1998. Amsterdam: IOS Press, 1998:3-5.

12. Clark WA, Molnar CE. The LINC:a description of the laboratory instrument computer. Ann NY Acad Sci 1964;115: 653-68.

13. Peckham BM, Slack WV, Carr WF, Van Cura LJ, Schultz AE. Computerized data collection in the management of uterine cancer. Clin Obstet Gynecol 1967; 10:1003-15.

14. Slack WV, Van Cura LJ. Computer-based patient interviewing. Postgrad Med 1968;43:68-74.

15. Slack WV, Van Cura LJ.Computer-based patient interviewing. Postgrad Med 1968;43:115-20.

16. Slack WV. Medical interviewing by computer. South Med Bul 1969;57:39-44

17. Slack WV, Van Cura LJ, Greist JH. Computers and doctors:use and consequences. Comput Biomed Res 1970;3:521-7.

18. Maultsby MC, Slack WV. A computerbased psychiatry history system. Arch Gen Psychiatry 1971;25:570-2.

19. Chun RWM, Van Cura LJ, Spencer M, Slack WV. Computer interviewing of patients with epilepsy. Epilepsia 1976; 17:371-5.

20. BanaDS, LevitonA, Swidler C, Slack WV, 
Graham JR. A computer-based headache interview:acceptance by patients and physicians. Headache 1980;20:85-9.

21. BanaDS, Leviton A, Slack WV, GeerDE Graham JR. Use of a computerized database in a headache clinic. Headache 1981;21:72-4.

22. Bennett SE, Lawrence RS, Fleischmann $A B$, Gifford CS, Slack WV. Profile of women practicing breast self-examination. JAMA 1983;249:488-91.

23. LevitonA, Slack WV, Bana D, Graham JR. Age-related headache characteristics. Arch Neurol 1984;41:762-4.

24. Slack WV. A history of computerized medical interviews. MD Comput 1984;1:52-9.

25. Mayne JG, Weksel W, Sholtz PN. Toward automating the medical history. Mayo Clin Proc 1968;43:1-25.

26. Mayne JG, Martin MJ. Computer-aided history acquisition. Med Clin North Am 1970;54:825-33.

27. Coombs GJ, Murray WR, Krahn, DW. Automated medical histories:factors determining patient performance. Comput Biomed Res 1970;3:178-81.

28. Grossman JH, Barnett GO, Mcguire MT, Swedlow DB. Evaluation of computeracquired patient histories. JAMA 1971; 215:1286-91.

29. Warner HR, Rutherford BD, Houtchens BA. A sequential Bayesian approach to history taking and diagnosis. Comput Biomed Res 1972;5:256-62.

30. Stead WW, Heyman A, Thompson HK, Hammond WE. Computer assisted interview of patients with functional headaches. Arch Intern Med 1972;129:1-12.

31. Simborg DW, Rikli AE, Hall P. Experimentation in medical history-taking JAMA 1969;210:1443-5.

32. Coddington RD, King TL. Automated, history taking in child psychiatry. Am J Psychiatry 1972;129:176-82.

33. Gottlieb GL, Beers RF, Bernecker C, Samter M. An approach to automation of medical interviews. Comput Biomed Res 1972; 5:99-107.

34. Greist JH, Gustafson DH, Stauss FF, Rowse GL, Laughren TP, Chiles JA. A computer interview for suicide-risk prediction. Am J Psychiatry 1973;130:1327. 32.

35. Rockhart JF, McLean ER, Hershberg PI, et al. An automated medical history system. Arch Intern Med 1973;132:348-58.

36. Schuman SH, Curry HB, Braunstein ML, Schneeweiss R, Jebaily GC, Glazer HM, Cahn JR, Crigler WH. A computer-administered interview on life events:improving patient-doctor communication. J Fam Pract 1975;2:263-9.

37. Pauker SG, Gorry GA, Kassirer JP,
Schwartz WB. Towards the simulation of clinical cognition:taking a present illness by computer. Am J Med 1976;60:981-96.

38. Lucas RW, Card WI, Knill-Jones RP, Watkinson G, Crean GP:Computer interrogation of patients. $\mathrm{Br}$ Med J 1976;2:623-5.

39. Lucas RW, Mullin PJ, Luna CB, McInroy DC. Psychiatrists and a computer as interrogators of patients with alcohol-related illnesses:a comparison. Br J Psychiatry 1977;131:160-7

40. Lucas RW, A study of patients' attitudes to computer interrogation. Int J Man-Machine Studies 1977;9:69-86.

41. Greist JH, Klein MH. Computer programs for patients, clinicians, and researchers in psychiatry. In: SidowskiJB, Johnson $\mathrm{JH}$, Williams TA, eds. Technology in Mental Health Care Delivery Systems. Norwood, Conn.: Ablex, 1980:161-82.

42. Carr AC, Ghosh A, Ancill RJ. Can a computer take a psychiatric history? Psychol Med 1983;13:151-8.

43. Carr AC, Ghosh A. Response of phobic patients to direct computer assessment. Brit J Psych 1983;142:60-5.

44. Skinner HA, Allen BA. Does the computer make a difference? Computerized versus face-to-face versus self-report assessment of alcohol, drug, and tobaccouse. J Consulting Clin Psych 1983;51:267-73.

45. Millstein SG, Irwin CE Jr. Acceptability of computer-acquired sexual histories in adolescent girls. J Pediatr 1983;103:815-9.

46. Tanser AR, Davies A. Archie:the use of a microcomputerin anallergy clinic. $\mathrm{Br} J \mathrm{Dis}$ Chest 1984;78:135-9.

47. Quaak MJ, Westerman RF, Schout JA, Hasman A, van Bemmel JH. Patient appreciations of computerized medical interviews. Med Info 1986;11:339-50.

48. Houziaux MO, Lefebve PJ. Historical and methodological aspects of computer-assis-ted medical history taking. Med Info 1986;11:129-43.

49. Lindberg G, Seensalu R, Nilsson LH, Forsell P, Kagar L, Knill-Jones RP. Transferability of a computer system for medical history taking and decision support in dyspepsia. A comparison of indicants for peptic ulcer disease. Scand J Gastroenterol Suppl 1987;128:190-6.

50. Haug PJ, Warner HR, Clayton PD, et al. A decision-driven system to collect the patient history. Comput Biomed Res 1987;20:193-207.

51. Pringle $M$. Using computers to take patient histories. Br Med J 1988;297:697-8.

52. Lutner RE, Roizen MF, Stocking CB, et al. The automated interview versus the personal interview. Do patient responses to preoperative health questions differ? Anesthesiology 1991;75:394-400.
53. Locke SE, Kowaloff HB, Hoff RG, et al. Computer-based interview for screening blood donors for risk of HIV transmission. JAMA 1992;268:1301-5.

54. Sanders GD, Owens DK, Padian N, Cardinalli AB, Sullivan AN, Nease RF. A computer-based interview to identify HIV risk behaviors and to assess patient preferences for HIV-related health states. In Gardner RM. Proceedings $19^{\text {sh }}$ Annual Symposium on Computer Applications in Medical Care. Philadelphia: Hanley \& Belfus, 1994:20-4.

55. Hasley S. A comparison of computerbased and personal interviews for the gynecologic history update. Obstet Gynecol 1995;85:494-8.

56. Vitkun SA, Gage JS, Anderson DH, Williams SA, Halpern-Lewis JG, Poppers PJ. Computerization of the preoperative anesthesia interview. Int $\mathrm{J}$ Clin Monit Comput 1995;12:71-6.

57. Kobak KA, Greist JH, Jefferson JW, Katzelnick DJ. Computer-administered clinical rating scales. Psychopharmacology (Berl) 1996;127:291-301.

58. Taenzer PA, Sauve L, Burgess ED, Milkavich $\mathrm{L}$, Whitmore B. The health interview:automated assessment in a multidisciplinary outpatient hypertension treatment program. MD Comput 1996;13:423-6.

59. Kohlmeier L, Mendez M, McDuffie J, Miller M. Computer-assisted selfinterviewing: a multimedia approach to dietary assessment. Am J Clin Nutr 1997;65 (Suppl 4):1275-81.

60. Bock B, Niaura R, Fontes A, Bock F. Acceptability of computer assessments among ethnically diverse, low-income smokers. Am J Health Promot 1999;13:299-304

61. SlackWV, Van CuraLJ.Patient reaction to computer-based medical interviewing. Comput Biomed Res 1968;1:527-31.

62. Starkweather JA. Computest:a computer language for individual testing, instruction, and interviewing. Psychol Rep 1965; 17:227-37.

63. Swedlow DB, Barnett GO, Grossman JH, Souder DE. A simple programming system ("DRIVER") for the creation and execution of an automated medical history. Comput Biomed Res 1972;5:90-8.

64. Angle HV, Carroll JA. Computer interview language:programming the on-line interactive computer. Behav Res Meth Instrumentation 1979;11:379-83.

65. Bloom SM, White RJ, Beckley RF, Slack WV. Converse:a means to write, edit, administer, and summarize computer-based dialogue. Comput Biomed Res 1978;11: 167-75.

66. Slack WV. Patient power:a 
patient-oriented value system. In: Jacques JA, ed. Computer Diagnosis and Diagnosis Methods: Proceedings of the Second Conference on Diagnostic Process held at the University of Michigan. Springfield, Ill: Charles C Thomas, 1972:3-7.

67. Slack WV. The patient's right to decide. Lancet 1977;2(8031):240.

68. Witschi J, Porter D, Vogel S, Buxbaum R, Stare FJ, Slack W. A computer-based dietary counseling system. J Am Diet Assoc 1976;69:385-90.

69. Slack W, Porter D, Witschi J, Sullivan M, Buxbaum R, Stare FJ. Dietary interviewing by computer. An experimental approach to counseling. J Am Diet Assoc 1976;69:514-7.

70. Fisher LA, Johnson TS, Porter D, Bleich HL, Slack WV. Collection of a clean voided urine specimen:a comparison among spoken, written, and computer-based instructions. Am J Public Health 1977;67:640-4.

71. SlackWV, Safran C, KowaloffHB, Pearce JP, Delbanco TL. A computer-administered health screening interview for hospital personnel. MD Comput 1995;12:2530.

72. Bleich HL, Beckley RF, Horowitz G, et al. Clinical computing in a teaching hospital. N Engl J Med 1985;312:756-64.

73. Slack WV, Bleich HL. The CCC system in two teaching hospitals:a progress report. Int J Med Inform 1999;54:183-96.

74. Van Cura LJ, Jensen NM, Greist JH, Lewis WR, Frey SR. Venereal disease: interviewing and teaching by computer. Am J Public Health 1975;65:1159-64.

75. Barry MJ, Mulley AG Jr, Fowler FJ, Wennberg JW. Watchful waiting vs immediate transurethral resection for symptomatic prostatism:the importance of patients' preferences. JAMA 1988;259: 3010-7.

76. Mulley AG. Supporting the patient's role in decision making. J Occup Med 1990; 32: 1227-8.

77. Brennan PF, Ripich S, Moore SM. The use of home-based computers to support persons living with AIDS/ARC. J Community Health Nurs 1991;8:3-14.

78. Gustafson DH, Bosworth $\mathrm{K}$, Hawkins RP, Boberg EW, Bricker E. CHESS:a computer-based system for providing information, referrals, decision support and social support to people facing medical and other health-related crises. In: Frisse ME, ed. Proceedings $16^{\text {th }}$ Annual Symposium on Computer Applicatins in Medical Care. New York: McGraw-Hill, 1992:1615.

79. Friedman RH, Kazis LE, Jette A, et al. A telecommunications system for monitoring and counseling patients with hypertension:impact on medication adherence and blood pressure control. Am J Hypertens 1996;9:285-92.

80. Gustafson DH, Hawkins R, Boberg E, et al. Impact of patient-centered, computerbased health information/support system. Am J Prev Med 1999;16:1-9.

81. Slack WV. Computer-based interviewing system dealing with nonverbal behavior as well as keyboard responses. Science 1971;171:84-8.

82. Lucas RW. Computer interrogation: investigation of patients' response times. Int Res Commun Systems J Med Sci 1974;2:1176.

83. Slack WV, Leviton A, Bennett SE, Fleischmann $\mathrm{KH}$, Lawrence RS. Relation between age, education, and time to respond to questions in a computer-based medical interview. Comput Biomed Res 1988;21:78-84.

84. Weizenbaum JE. ELIZA:a computer program for the study of natural language communication between man andmachine. Commun Assoc Comput Mach 1966;. 9:36-45.

85. Colby KM, Watt JB, Gilbert JP. A computer method of psychotherapy: preliminary communication. J Nerv Ment Dis 1966;142:148-52.

86. Rogers CR. Client-centered therapy Boston:Houghton Mifflin, 1965.

87. Selmi PM, Klein MH, Greist JH, Sorrel SP, Erdman HP. Computer-administered cognitive-behavioral therapy for depression. Am J Psychiatry 1990;147:51-6.

88. Beck AT, Rush AJ, Shaw BF, Emery G Cognitive Therapy of Depression. New York: Guilford Press, 1979.

89. Hoffmann M, Hock C, Muller-Spahn F. Computer-based cognitive training in Alzheimer's disease patients. Ann New York Acad Sci 1996;777:249-54.

90. BloodGW. A behavioral-cognitive therapy program for adults who stutter:computers and counseling. J Commun Disord 1995;28:165-85.
91. Slack WV, Slack CW. Patient-computer dialogue. NEngl JMed 1972;286:1304-9.

92. Slack WV, Slack CW. Talking to a computer about emotional problems:a comparative study. Psychother Theory Res Pract 1977;14:156-64

93. Slack WV, Porter D, Balkin P, Kowaloff HB, Slack CW. Computer-assisted soliloquy as an approach to psychotherapy. MD Comput 1990;7:37-42, 58.

94. Spielberger CD. The measurement of state and trait anxiety:conceptual and methodological issues. In: Levi L, ed. Emotions: their Parameters and Measurement. New York: Raven Press, 1975:713-25.

95. Freud SA.A General Introduction to Psychoanalysis. New York: Pocket Books, 1921.

96. Watson JB. Behaviorism. New York: Norton, 1924

97. Skinner BF. Science and Human Behavior. New York: Macmillan, 1953.

98. Slack WV. The handheld calculator. MD Comput 1991;8:8-10.

99. Harris Pole, 1999, reported in NUA Internet Surveys, www.nua.ie/surveys.

100. Ferguson T. Health Online: How to Find Health Information, Support Groups, and Self Help Communities in Cyberspace. Reading, Massachusetts: AddisonWesley, 1996.

101. Horowitz GL, Bleich HL. PaperChase:a computer program to search the medical literature. N Engl J Med 1981;305:924-30.

102. Scolamiero SJ. Support groups in cyberspace. MD Comput 1996;14:12-7.

103. Slack WV. The issue of privacy. MD Comput 1997;14:8-10.

104. Slack WV. Private information in the hands of strangers. MD Comput 1997;14:83-6.

Address of the author:

Warner V. Slack, M.D.

Center for Clinical Computing,

350 Longwood Avenue,

Boston, MA 02115, USA.

E-mail:wslack@caregroup.harvard.edu 